\title{
Forest cover mapping in Central Spain with IRS-WIFS images and multi-extent textual-contextual measures
}

\author{
S. SAURA ${ }^{1}$ and J. SAN MIGUEL-AYANZ ${ }^{2}$ \\ ${ }^{1}$ E.T.S. Ingenieros Industriales. Universidad de Castilla-La Mancha. Campus \\ Universitario s/n. 13071. Ciudad Real. Spain \\ e-mail: sfsaura@ind-cr.uclm.es \\ ${ }^{2}$ EC-DG Joint Research Centre. Space Applications Institute. EGEO-Natural \\ Hazards (TP 263). Via Fermi, Ispra (Va). I-21020. Italy
}

(Received 20 October 2000; in final form 25 April 2001)

\begin{abstract}
An area of $95200 \mathrm{~km}^{2}$ in central Spain was mapped using IRS-WiFS data to test the potential use of this imagery for regional cover type mapping. In addition to the original WiFS red and NIR spectral bands, textural-contextual images were computed as means and variances of the NDVI and the NIR and red bands over windows of different sizes $(3 \times 3$ to $50 \times 50$ pixels $)$ and included in the analysis. An iterative classification of the imagery was performed using a maximum likelihood classifier with feature selection by spectral separability indices. Results obtained in this study show that IRS-WiFS is a valuable source of information for forest cover mapping at regional scales. Semi-natural areas (comprising forests, shrubs and grasslands) and forests were classified with $93 \%$ and $83 \%$ mean accuracy, respectively. The classification accuracy of most cover types increased when textural-contextual information computed over large windows (larger than those reported in the literature) were used for classification in combination with spectral data.
\end{abstract}

\section{Introduction}

The IRS-1C Wide Field Sensor (WiFS) is a relatively new sensor that has provided data since 1996. WiFS has a swath width of $810 \mathrm{~km}$, ground spatial resolution of $188 \mathrm{~m}$ and two spectral bands in the range of the red $(\mathrm{R}, 620-680 \mu \mathrm{m})$ and the near-infrared (NIR, 770-860 $\mu \mathrm{m}$ ) wavelengths (NRSA 1995). These spatial and spectral resolutions make WiFS a potentially useful data source for regional forest cover analyses.

Previous remote sensing studies used contextual and textural information to increase image classification accuracy. Accuracy was found to increase when low pass filter images, which reduce image noise and take into account the characteristics of the neighbourhood pixels (context), were combined with non-filtered spectral data (Atkinson et al. 1985) for image classification. Contextual information derived using majority filters, probabilistic label relaxation, and other similar techniques ( Richards 1993, Kartikeyan et al. 1994, Kwang 1996) have also been used for post-classification refinement. Small windows (3 by 3 pixels) were used to extract the contextual 
information. Textural measures, such as variances, have also been used in the classification of remotely sensed data to increase the classification accuracy ( Kushwaha et al. 1994, San Miguel-Ayanz and Biging 1996, Chica-Olmo and Abarca-Hernández 2000). Small windows, up to a maximum of 9 pixels by 9 pixels, were used to compute texture variables (Hodgson 1998). However, as noted by Hodgson (1998), human interpreters of satellite sensor images gain useful information for the classification by analysing the pattern in much larger windows than those commonly considered by digital classifiers. In fact, human interpreters may use a hierarchy of windows of different extents to extract the useful information for the classification (Hodgson 1998).

This study shows the potential of using IRS-WiFS imagery for cover type mapping at the regional scale. It also demonstrates that the inclusion of textural and contextual information extracted from windows of different sizes (including much larger sizes than those commonly used for satellite sensor imagery classification) along with per-pixel spectral data results in increased image classification accuracy.

\section{Methods}

\subsection{Data}

An IRS-1C-WiFS image acquired on 9 September 1998 was geometrically rectified to the CORINE European Land Cover Database (CEC 1993) with sub-pixel accuracy. The $95200 \mathrm{~km}^{2}$ study area selected on the image comprised both typically Mediterranean vegetation types (e.g. Quercus ilex, Pinus halepensis) and others that are characteristic of more humid areas (e.g. Quercus pyrenaica).

Independent classification training and accuracy assessment polygons were selected on CORINE, which included non-natural classes (irrigated land, olive groves, vineyards, urban areas, etc.) to ensure the data normality required by the maximum likelihood classifier (MLC). CORINE does not differentiate between evergreen and deciduous broad-leaved forests, but the latter presented a much greater NIR response in the analysed image, which allowed defining two independent cover classes with the aid of the Natural Vegetation Map of Europe (NVME) (CEC 1987). The heterogeneous class 'mixed forest', composed both of coniferous and broad-leaved species, was not considered as a separate forest type, and was merged with the other

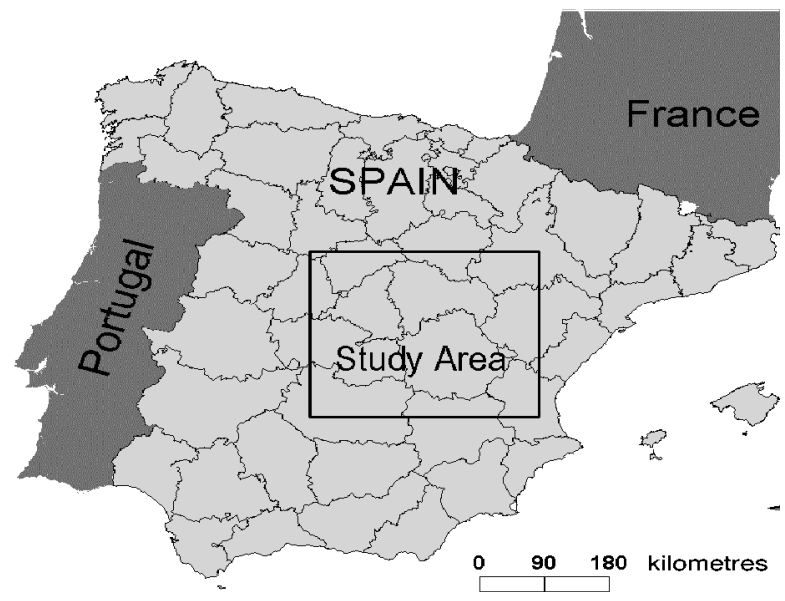

Figure 1. Location of the study area, delimited by the square on the map of Spain. 
forest classes. The two CORINE shrub classes ('sclerophyllous vegetation' and 'transitional woodland and shrub') were merged in a unique class.

\subsection{Derivation of new images}

A new set of textural-contextual images was generated and included in the analysis. The images were computed as means and variances of the NDVI and the $\mathrm{R}$ and NIR bands in windows of $3 \times 3,7 \times 7,15 \times 15,20 \times 20,30 \times 30,40 \times 40$ and $50 \times 50$ pixels to total 42 new images. The mean or variance of the spectral values of all the pixels in the window was computed and assigned to the central pixel. To make the classification feature selection process computationally affordable, the 42 textural-contextual images were reduced to their 10 first principal components, which accounted for more than $99 \%$ of the variance of this new information.

Deciduous broad-leaved forests and irrigated agricultural areas were not spectrally separable with the original WiFS bands, as both are characterised by a high NIR and relatively low red radiance (figure 2). However, the use of texturalcontextual information permits the separation of these classes. Irrigated lands are usually located next to other non irrigated agricultural areas with high red radiance, while deciduous forests are located on natural surroundings, typically with fairly low
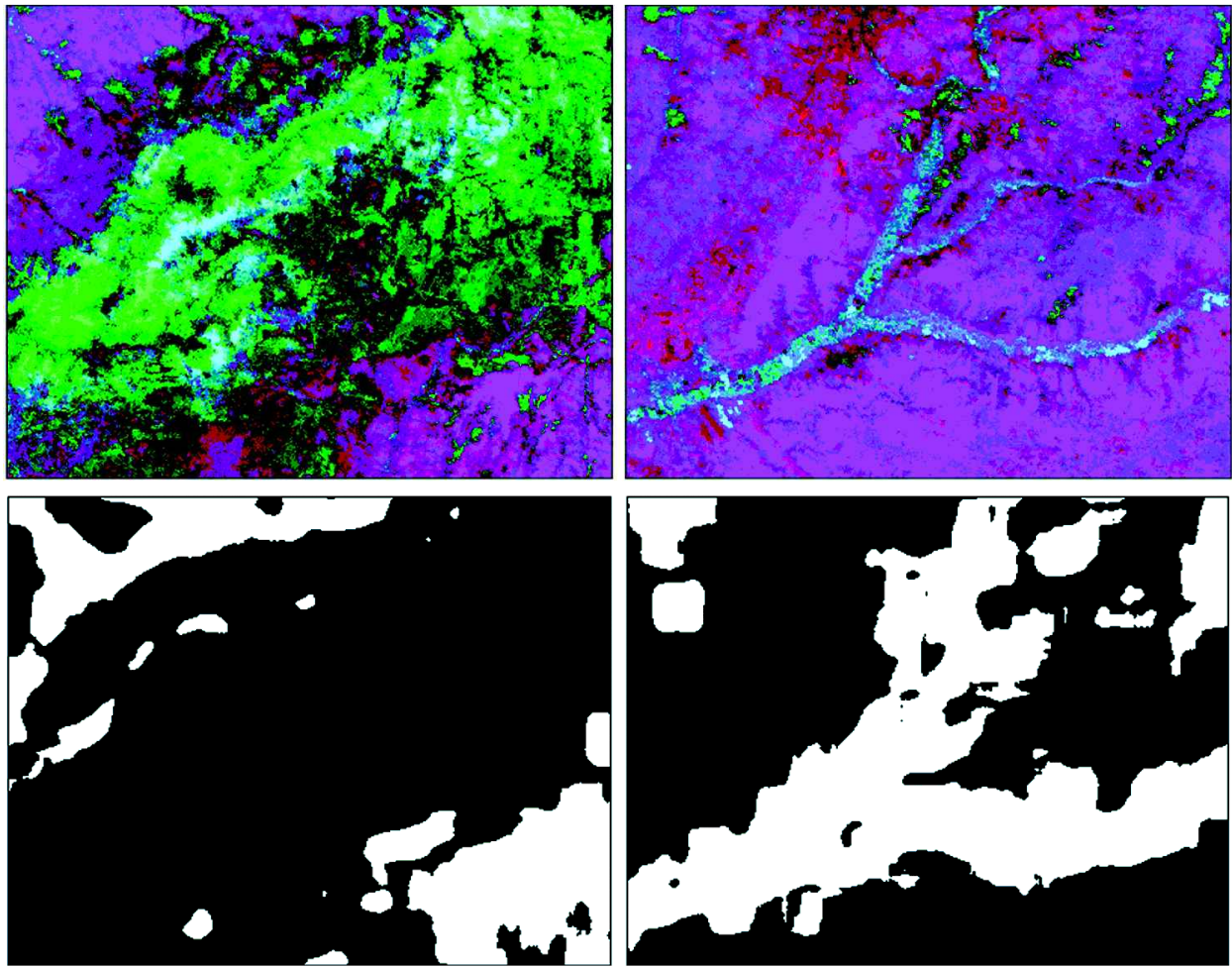

Figure 2. Two zones of the study area presenting deciduous broad-leaved forest (left) and irrigated agricultural land (right). The upper images (400 by 311 pixels) are colour composites with the red and NIR bands and the NDVI displayed respectively as the RGB components, where both cover types present a blue-cyan colour. Below them, and for the same zones, are shown in white the areas with a high variance in the red band in 30 pixel $\times 30$ pixel windows. 
red radiance. The variance of the red band computed over a large extent $(\mathrm{a} 30 \times 30$ pixel window) captures this information (figure 2) and enables one to appropriately discriminate these spectrally similar cover types on the basis of their degree of contrast with neighbourhood cover types.

In addition to the two original red and NIR WiFS bands and the texturalcontextual information, also the NDVI, the NIR/R ratio, and the first principal component of the WiFS bands were included in the analysis. These have been used by some authors to increase cover type classification accuracy ( San Miguel-Ayanz and Biging 1996). Signatures corresponding to all these images were extracted from the training polygons selected on CORINE.

\subsection{Classification}

An iterative classification method based on the MLC was applied in this study. In this approach, one cover type is classified in each iteration, allowing the selection of a different number and set of features for the classification of each of the remaining unclassified cover types. The process results in an increase in classification accuracy when compared to that obtained by single step classifiers (San Miguel-Ayanz and Biging 1996). The Transformed Divergence, the Jeffries-Matusita, and the weighted versions of these spectral separability indices, which include class prior probabilities, were used to select the features that best classified each of the forest classes (Richards 1993). Classifications with the set of features that presented the best minimum and mean separability provided by each of these indices were performed. The set that provided the highest accuracy for each of the cover types was selected. The number of features was varied from 2 to the number in which a significant decrease in classification accuracy was reported. The cover type that presented the highest accuracy was classified and masked, so that the iterative classification method would continue with the remaining unclassified portion of the image. The first step was the classification of non-natural areas, in which the NIR and red bands were used. Then the iterative classification proceeded with the forest and semi-natural cover types. Only one of the non-natural classes (irrigated agricultural areas) was classified using textural-contextual information, since it results in a great reduction of the confusion between that class and deciduous broad-leaved forests, as described earlier (figure 2).

\section{Results and conclusion}

Accuracy analysis was performed through the comparison of the classified image with a reference data set obtained from the intersection of CORINE and the NVME. Neither CORINE nor NVME can be considered as ground truth data, since they are the result of two different mapping procedures, one mainly based on remote sensing (CORINE) and the second based on ground sampling techniques. No rigorous accuracy assessment of either data set is available. However, they constitute the only European reference maps for comparison with an eventual regional classification using WiFS imagery. The classification accuracy results are presented in table 1. These include also the accuracy of a classical single-step classification with a MLC using only the per-pixel spectral information of the two original WiFS bands. Significant increases in classification accuracy were obtained for all the classes when including textural-contextual information in the classification (except shrubs). Mean accuracy (mean of producer and user accuracy) increased noticeably for evergreen $(14 \%)$ and deciduous broad-leaved (35\%) forests. Confusion of this latter class with irrigated agricultural lands was diminished (table 2) by including large window-size 
Table 1. Accuracy assessment for the iterative classification (columns 2, 3) and the single step classification (columns 3,4). Producer accuracy is the percentage of reference areas of a given type classified correctly, while user accuracy is the percent of correctly classified areas within those labelled in a certain cover type by the classifier.

\begin{tabular}{|c|c|c|c|c|c|}
\hline & \multicolumn{2}{|c|}{$\begin{array}{l}\text { Textural-contextual } \\
\text { iterative classification }\end{array}$} & \multicolumn{2}{|c|}{$\begin{array}{l}\mathrm{R} \text { and NIR single step } \\
\text { classification }\end{array}$} & \multirow[b]{2}{*}{$\begin{array}{l}\text { Mean accuracy } \\
\text { increase (5) }\end{array}$} \\
\hline & $\begin{array}{c}\text { User } \\
\text { accuracy } \\
(\%)\end{array}$ & $\begin{array}{l}\text { Producer } \\
\text { accuracy } \\
(\%)\end{array}$ & $\begin{array}{c}\text { User } \\
\text { accuracy } \\
(\%)\end{array}$ & $\begin{array}{l}\text { Producer } \\
\text { accuracy } \\
(\%)\end{array}$ & \\
\hline $\begin{array}{l}\text { Deciduous broad-leaved forest } \\
\text { (DBF) }\end{array}$ & 91.87 & 98.48 & 46.02 & 74.68 & +34.83 \\
\hline $\begin{array}{l}\text { Evergreen broad-leaved forest } \\
\text { (EBF) }\end{array}$ & 49.21 & 57.18 & 50.00 & 27.87 & +14.26 \\
\hline Coniferous forest $(\mathrm{CF})$ & 54.42 & 75.93 & 42.84 & 77.73 & +4.89 \\
\hline Shrubs (SH) & 67.14 & 48.20 & 66.55 & 55.06 & -3.14 \\
\hline Natural grassland (NG) & 56.94 & 45.18 & 32.77 & 45.99 & +11.68 \\
\hline Water bodies (WB) & 100 & 99.64 & 100 & 98.20 & +0.72 \\
\hline Non natural areas (NN) & 94.50 & 92.16 & 95.15 & 86.53 & +2.49 \\
\hline
\end{tabular}

Table 2. Confusion matrix for the iterative classification of WiFS data. Main diagonal elements are percentage of the reference data correctly labelled by the classifier for each cover type (producer accuracy). See table 1 for the description of class acronyms.

\begin{tabular}{lccccccc}
\hline & \multicolumn{7}{c}{ Reference data (\%) } \\
\cline { 2 - 8 } Classification & DBF & EBF & CF & SH & NG & WB & NN \\
\hline DBF & 98.48 & 0.82 & 0.36 & 0 & 0 & 0 & 0 \\
EBF & 0 & 57.18 & 16.12 & 20.61 & 1.46 & 0 & 0.70 \\
CF & 1.01 & 34.45 & 75.93 & 18.19 & 8.01 & 0 & 0.46 \\
SH & 0 & 4.77 & 7.43 & 48.20 & 36.70 & 0 & 4.13 \\
NG & 0 & 0 & 0 & 3.24 & 45.18 & 0 & 2.55 \\
WB & 0 & 0 & 0 & 0 & 0 & 99.64 & 0 \\
NN & 0.51 & 2.78 & 0.16 & 9.76 & 8.65 & 0.36 & 92.16 \\
\hline
\end{tabular}

contextual information in the classification (figure 2). Shrubs and natural grasslands were confused with several other forest cover classes and particularly among themselves (table 2). The overall map classification accuracy was $72 \%$. If the three types of forests are merged in a single forest class $83 \%$ accuracy is achieved.

These results show that WiFS is a valuable source of information for forest cover mapping and land stratification for forest inventory at the regional scale. In addition, the multi-extent textural-contextual information helped in discriminating spectrally similar classes, especially when computed over larger windows than those previously used in satellite sensor image classification.

\section{Acknowledgments}

This study was performed at the Space Applications Institute (Joint Research Centre of the European Commission) and funded through a research grant from the Ministerio de Educación y Cultura of Spain to Santiago Saura Martínez de Toda. Anonymous reviewers made valuable comments on a previous version of this Letter. 


\section{References}

Atkinson, P., Cushnie, J. L., Townshend, J. R. G., and Wilson, A., 1985, Improving Thematic Mapper land cover classification using filtered data. International Journal of Remote Sensing, 6, 955-961.

Chica-Olmo, M., and Abarca-Hernández, F., 2000, Computing geostatistical image texture for remotely sensed data classification. Computers and Geosciences, 26, 373-383.

Commission des Communautés Européens, 1987, Carte de la végétation naturelle des Etats membres des Communautés européennes et du Conseil de l'Europe. Office des publications officielles des Communautés européennes. Luxembourg.

Commission of the European Communities, 1993, CORINE Land Cover: guide technique. Report EUR 12585 EN. Office for Publications of the European Communities. Luxembourg.

Hodgson, M. E., 1998, What size for image classification? A cognitive perspective. Photogrammetric Engineering and Remote Sensing, 64, 797-807.

Kartikeyan, B., Gopalakrishna, B., Kalumbarme, M. H., and Majumder, K. L., 1994, Contextual techniques for classification of high and low resolution remote sensing data. International Journal of Remote Sensing, 5, 1037-1051.

Kushwaha, S. P. S., Kuntz, S., and Oesten, G., 1994, Applications of image texture in forest classification. International Journal of Remote Sensing, 15, 2273-2284.

KWNAG E. KIM., 1996, Adaptive majority filtering for contextual classification of remote sensing data. International Journal of Remote Sensing, 17, 1083-1087.

NRSA, 1995, IRS-1C Data User's Handbook (Hyderabad, India: National Remote Sensing Agency).

RichaRd, J. A., 1993, Remote sensing digital image analysis: an introduction (Berlin: Springer-Verlag).

San Miguel-Ayanz, J., and Biging, G. S., 1996, An iterative classification approach for mapping natural resources from satellite imagery. International Journal of Remote Sensing, 17, 957-981. 